\title{
Supporting Information \\ A Vesicle-based Gel via Polyelectrolyte-Induced Adhesion: Structure, Rheology, and Response
}

\author{
Rui Cao ${ }^{a}$, Deepak Kumar ${ }^{a, b}$, Anthony D. Dinsmore ${ }^{a, *}$ \\ ${ }^{a}$ Department of Physics, University of Massachusetts, Amherst MA \\ ${ }^{b}$ Department of Physics, Indian Institute of Technology Delhi, New Delhi, India \\ *Corresponding author: dinsmore@umass.edu
}

Online supplementary materials.

Here we provide additional details on the following topics:

I. Images of the $1-\mu \mathrm{m}$-scale vesicle gel.

II. Confocal fluorescence image of a vesicle 'superparticle.'

III. Gel survives osmotic shock

IV. Vesicle gel exposed to SDS micelles

V. Histogram of radii of vesicles.

VI. Permeability of the vesicle-gel to fluorescein and FITC-labeled dextran.

VII. Permeability of the vesicle-gel to Rhodamine-6G.

VIII. Plots of $\lambda$ and $G^{\prime}$ vs. $W$.

\section{Images of the 1- $\mu \mathrm{m}$-scale vesicle gel.}

Fig. S1 shows images of the 1- and 10- $\mu \mathrm{m}$ vesicle gel. The top row is a repeat of Fig. 1 of the main text, for comparison, and the bottom row shows the images within samples made from 1- $\mu \mathrm{m}$ scale vesicles with the same PDADMAC concentrations, $c_{\mathrm{p}}$.

(a)
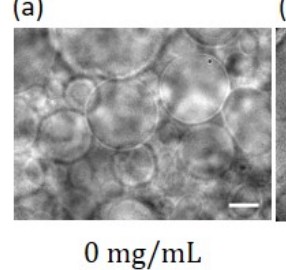

(b)

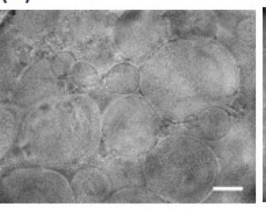

$0.0069 \mathrm{mg} / \mathrm{mL}$ (c)

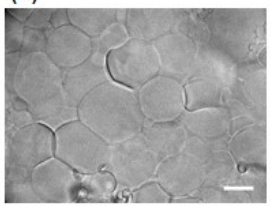

(d)

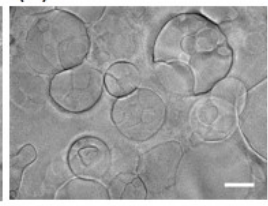

$0.69 \mathrm{mg} / \mathrm{mL}$ (e)

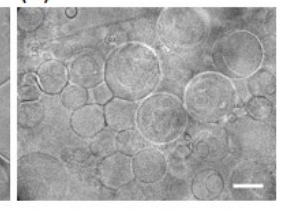

$5.8 \mathrm{mg} / \mathrm{mL}$
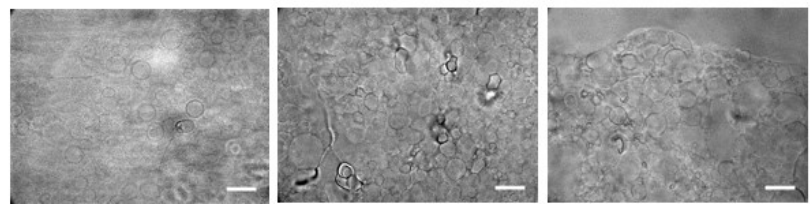

C[PDADMAC]

Fig. S1: Vesicle-gel morphology vs. $c_{p}$ for both $10-\mu \mathrm{m}$-scale (above the line) and 1- $\mu \mathrm{m}$-scale (below the line) vesicles. The scale bars are $10 \mu \mathrm{m}$. In the absence of polymer (a), vesicles were freely suspended in both cases. (b) With low $c_{p}=0.0069 \mathrm{mg} / \mathrm{mL}$, vesicles showed weak adhesion in both cases. (c) With $c_{p}=0.069 \mathrm{mg} / \mathrm{mL}$, adhesion was stronger and a clearly visible network formed. $(\mathrm{d}, \mathrm{e})$ With $C_{P}=0.69$ and $5.8 \mathrm{mg} / \mathrm{mL}$, vesicular "superparticles" were found in the $10-\mu \mathrm{m}$ scale vesicles but were not observed in the $1-\mu \mathrm{m}$ scale vesicles. All of the samples with $C_{P} \geq 0.0069 \mathrm{mg} / \mathrm{mL}$ showed solid-like behavior under shear and are therefore referred to as "vesicle gels." Scale bars are $10 \mu \mathrm{m}$. 


\section{Confocal fluorescence image of a vesicle 'superparticle.'}

Fig. S2 shows an image of a 'superparticle' formed with $400 \mathrm{kDa}$ PDADMAC with $c_{\mathrm{P}}=28 \mathrm{mg} / \mathrm{mL}$ and 0.1 mol\% Rh-DOPE added. These internal compartments were only found in this region of the concentration axis.

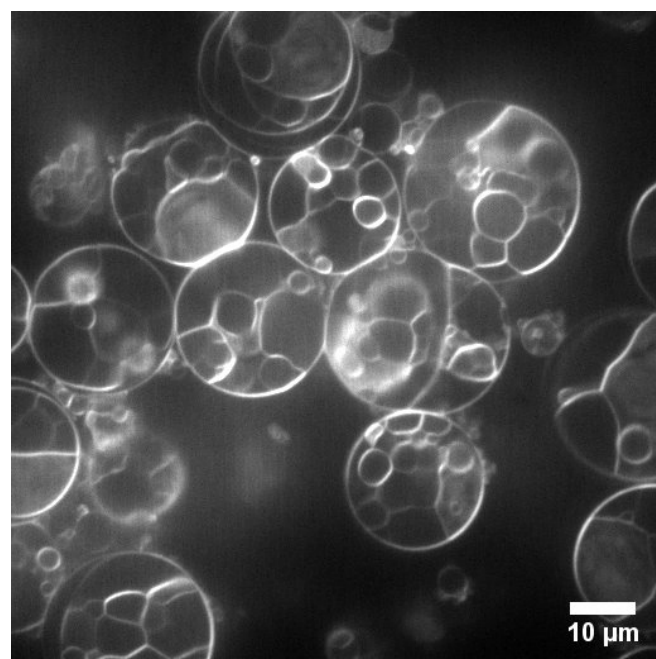

Fig. S2: Confocal fluorescence image of a vesicle 'superparticle' obtained at high polymer concentration.

\section{Gel survives osmotic shock.}

Fig. S3 shows vesicle gel can stand osmotic shock up to $-40 \mathrm{mOsm} / \mathrm{L} .10 \mu \mathrm{L}$ vesicle gel $\left(c_{p}=0.069 \mathrm{mg} / \mathrm{mL}\right.$, osmolarity $=187 \mathrm{mOsm} / \mathrm{L}$ ) was exposed to $100 \mu \mathrm{L}$ of $177,167,157,147 \mathrm{mOsm} / \mathrm{L}$ glucose solution. No significant vesicle destruction was observed after $48 \mathrm{~h}$.
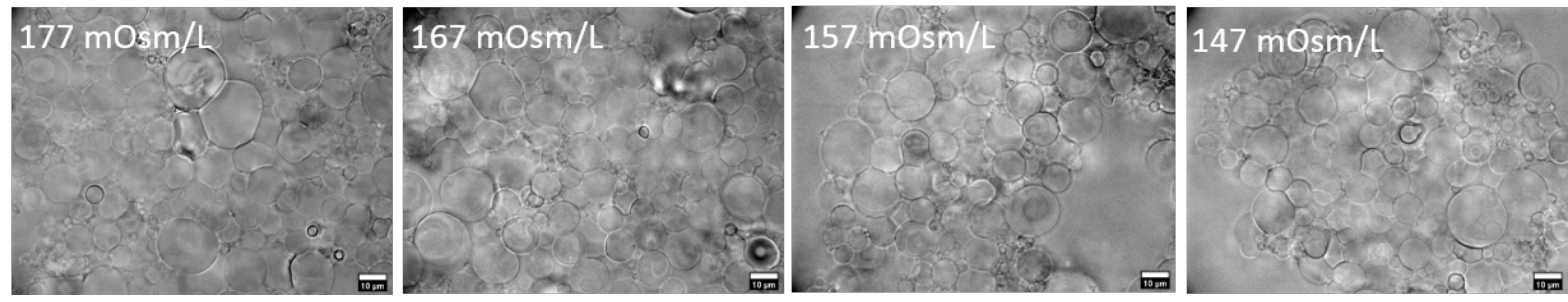

Fig. S3: $10 \mu \mathrm{L}$ vesicle gel $\left(c_{p}=0.069 \mathrm{mg} / \mathrm{mL}\right.$, osmolarity $\left.=187 \mathrm{mOsm} / \mathrm{L}\right)$ was exposed to $100 \mu \mathrm{L}$ of 177,167 , 157, $147 \mathrm{mOsm} / \mathrm{L}$ glucose solution. We observed no significant vesicle destruction after 48 hours. 


\section{Vesicle gel exposed to SDS micelles}

Fig. S4 shows the result of $20 \mu \mathrm{L}$ vesicle gel ( $\left.c_{\mathrm{p}}=0.069 \mathrm{mg} / \mathrm{mL}, 180 \mathrm{mOsm} / \mathrm{L}\right)$ exposed to $5 \mu \mathrm{L}$ sodium dodecyl sulfate $(S D S)$ surfactant (concentration $=8.2 \mathrm{mM}$ ) in glucose solution $(180 \mathrm{mOsm} / \mathrm{L})$. We observed that adhesion disappeared between some vesicles and other vesicles were destroyed.

(a)

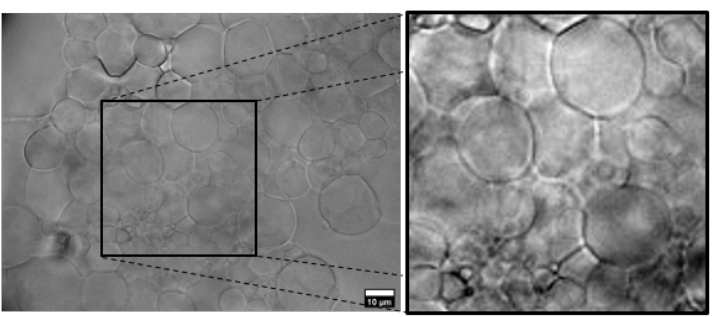

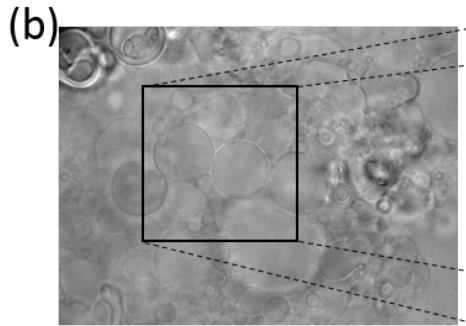

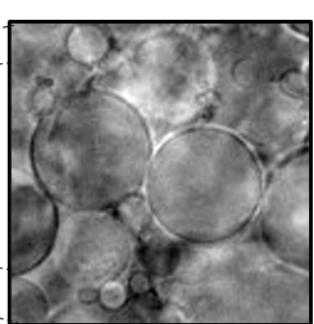

Fig. S4 (a): vesicle gel morphology ( $c_{p}=0.069 \mathrm{mg} / \mathrm{mL}, 180 \mathrm{mOsm} / \mathrm{L}$ ) before exposure to SDS solution. (b) Vesicle morphology $10 \mathrm{~min}$ after vesicle gel was exposed to SDS solution (8.2 mM, $180 \mathrm{mOsm} / \mathrm{L})$.

\section{Histogram of radii of vesicles.}

Fig. S5 shows histograms of the measured radii for vesicles that were included in the measurements of $\lambda$ to quantify adhesion.

(a)

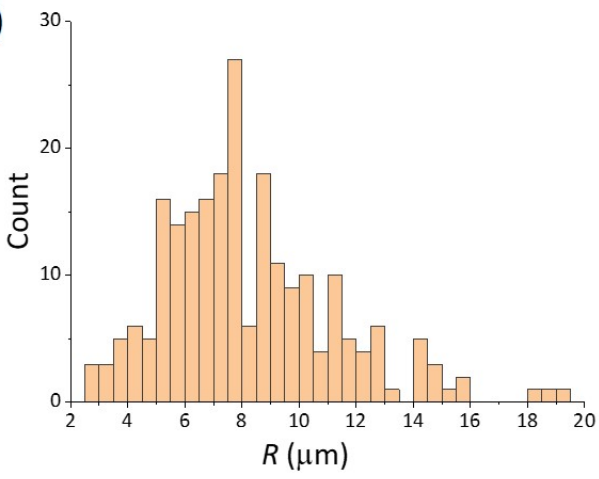

(b)

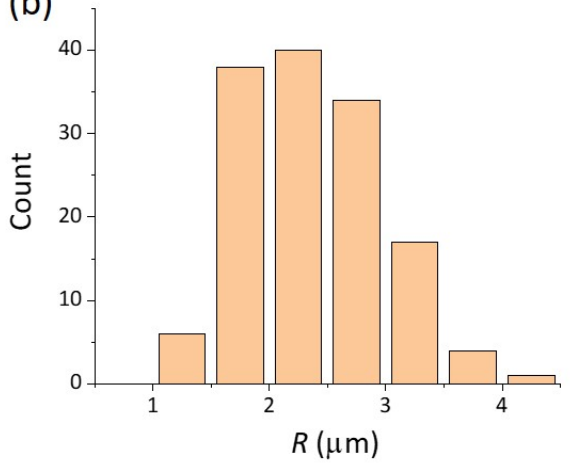

Fig. S5. Histograms of measured radius values for (a) the 10- $\mu \mathrm{m}$ scale vesicle gel and (b) the 1- $\mu \mathrm{m}$ vesicle gel. The mean values were $8.2 \mu \mathrm{m}$ and $2.4 \mathrm{~m}$, respectively. However, as described in the text, the latter distribution leaves out the smaller vesicles, so it does not provide an accurate measure of the population mean. 


\section{Permeability of the vesicle-gel to fluorescein and FITC-labeled dextran.}

Fig. S6 $(a, b, c)$ shows $c_{p}=0.0069 \mathrm{mg} / \mathrm{mL}$ is the critical concentration of fluorescein penetration through DOPC membranes. Vesicles were dispersed at this concentration. No significant penetration was observed when $c_{p} \leq 0.00069 \mathrm{mg} / \mathrm{mL}$ after 27 hours. Fig. S6(d, e, f) shows FITC-dextran can penetrate through lipid membrane of vesicle gel $\left(c_{p}=0.069 \mathrm{mg} / \mathrm{mL}\right)$ as well.

(a)
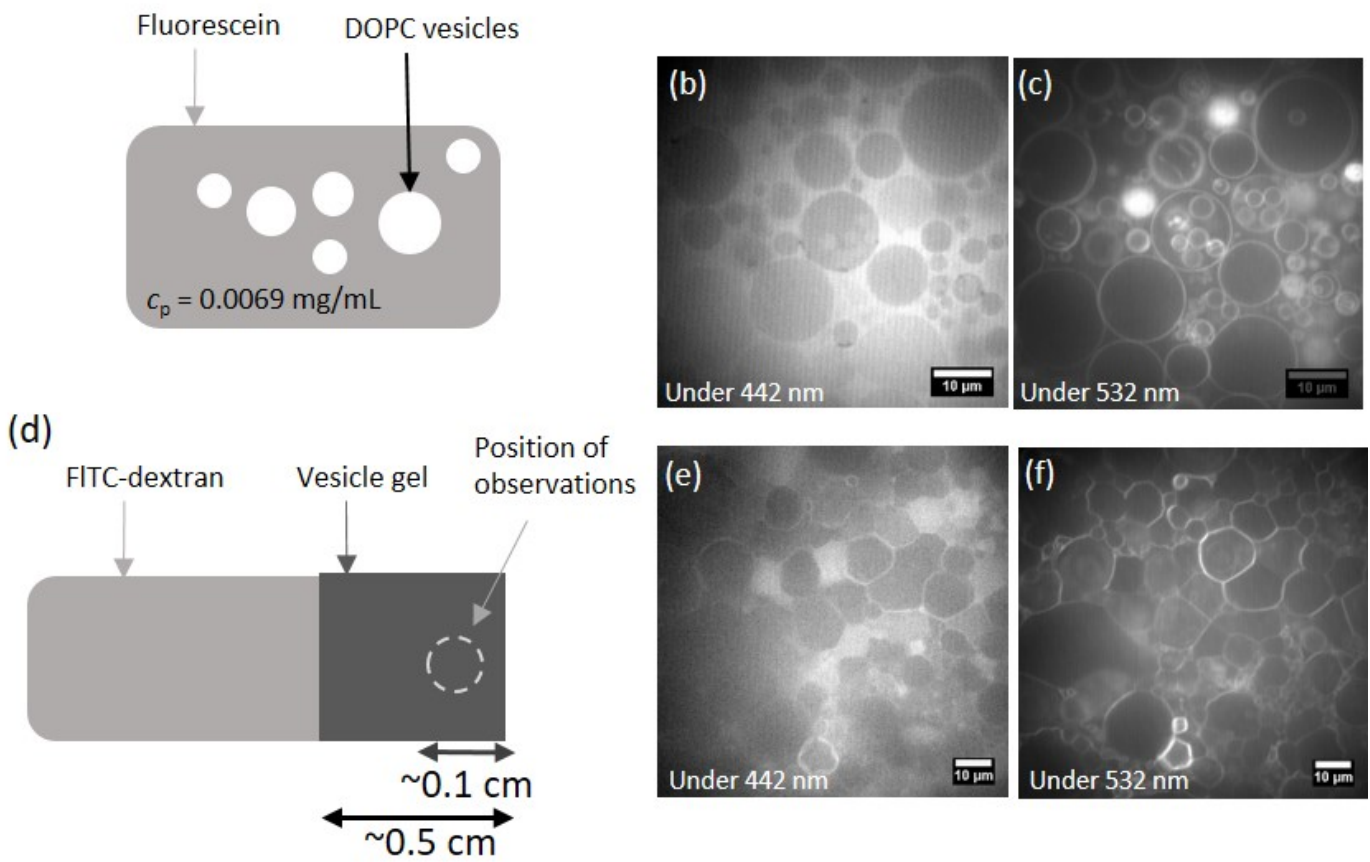

Fig. S6: (a) DOPC vesicles (0.1\% Rh-DOPE doped) mixed with osmolarity-balanced fluorescein solution under $c_{p}=0.0069 \mathrm{mg} / \mathrm{mL}$. (b, c) Permeation of the dye is clearly seen $2.5 \mathrm{~h}$ later. The left images are obtained with blue ( $442 \mathrm{~nm}$ peak) excitation and show fluorescein emission. The right-hand column is with green excitation, showing the Rh-DOPE lipid dye. (d) SLPC vesicle gel was exposed to an osmolarity balanced FITC-dextran solution $\left(0.52 \mathrm{mM}, c_{p}=0\right)$. (e, f) Some vesicles were permeated after $24 \mathrm{~h}$. 


\section{Permeability of the vesicle-gel to Rhodamine-6G.}

To test cationic dye permeability, we sealed $40 \mu \mathrm{L}$ of osmolarity-balanced solution of Rhodamine-6G perchlorate $\left(0.1 \mathrm{mM}, c_{p}=0\right.$, glucose added) next to $30 \mu \mathrm{L}$ of vesicle gel $\left(c_{p}=0.069 \mathrm{mg} / \mathrm{mL}\right)$ in a chamber like Fig. 7(a). We observed that Rhodamine-6G can permeate on and through membranes within $1 \mathrm{~h}$ as shown in Fig. S7 (c). A significant penetration was observed after $24 \mathrm{~h}$ as shown in Fig. S7(d). Our control experiment in Fig. S7(a) showed that Rhodamine-6G permeated through SLPC membranes within 10 min even in the absence of PDADMAC. DOPC membranes were also permeated by the Rhodamine-6G, as shown in Fig. S7(b). Therefore, we attribute the permeation of gel to the interaction between the membranes and Rhodamine-6G independent of PDADMAC.
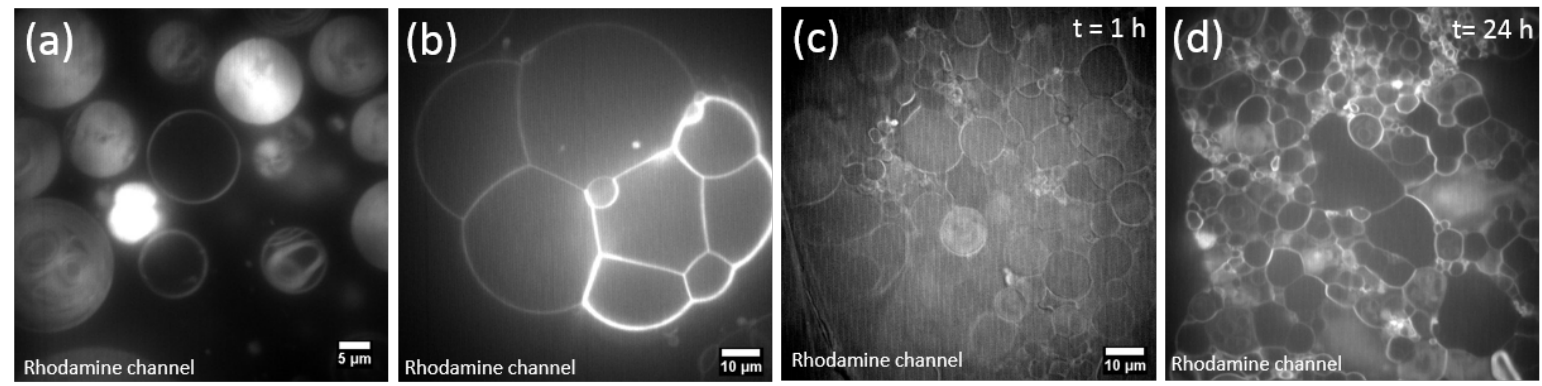

Fig. S7: (a) Rhodamine-6G permeates on and through free SLPC vesicles $\left(c_{p}=0\right)$. (b) Rhodamine-6G permeated on and through free DOPC vesicles $\left(c_{p}=0\right)$. (c) Rhodamine-6G permeates on and through SLPC vesicle gel $\left(c_{p}=0.069 \mathrm{mg} / \mathrm{mL}\right) 1$ hour after being put aside. (d) Rhodamine-6G permeated on and through an SLPC vesicle gel $\left(c_{p}=0.069 \mathrm{mg} / \mathrm{mL}\right) 24 \mathrm{~h}$ after exposure.

\section{Plots of $\lambda$ and $G^{\prime}$ vs. W.}

Figure $S 8$ shows how effective adhesion strength $(\lambda)$ and $\mathrm{G}^{\prime}\left(\omega=0.1 \mathrm{rad} / \mathrm{s}, \gamma_{0}=2.8 \%\right)$ vary with $W / \tau_{\text {mean }}$.

(a)

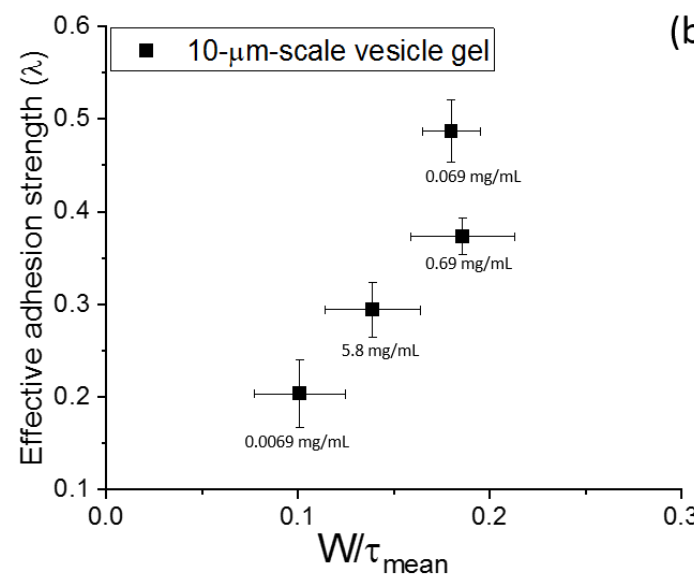

(b)

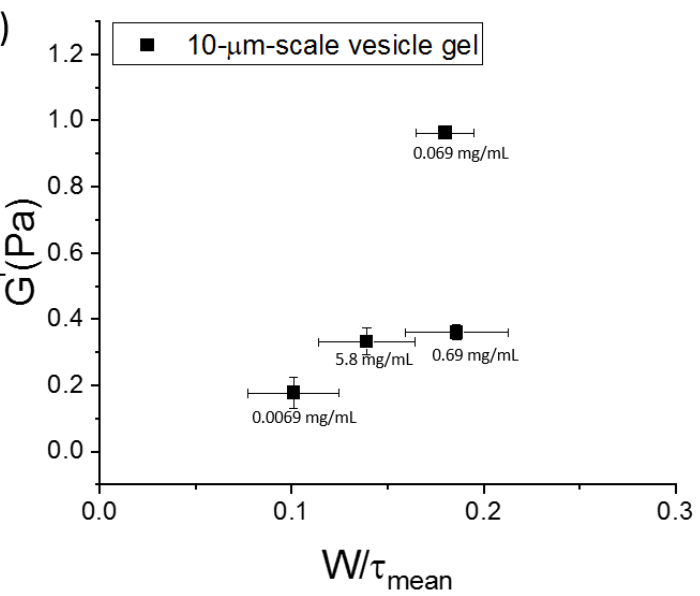

Fig S8. (a) A plot of effective adhesion strength $(\lambda) v s$. measured $W / \tau_{\text {mean. }}$ (b) $G^{\prime}\left(\omega=0.1 \mathrm{rad} / \mathrm{s}, \gamma_{0}=2.8 \%\right) v s$. measured $W / \tau_{\text {mean }}$. 